\title{
Adapting Evidence-Based Practices to Improve Library Instruction: Using customized tools to support peer mentoring and observation
}

\author{
Mary K. Oberlies, Kristin Buxton \& Annie Zeidman-Karpinski
}

To cite this article: Mary K. Oberlies, Kristin Buxton \& Annie Zeidman-Karpinski (2019): Adapting Evidence-Based Practices to Improve Library Instruction: Using customized tools to support peer mentoring and observation, New Review of Academic Librarianship, DOI: 10.1080/13614533.2019.1628078

To link to this article: https://doi.org/10.1080/13614533.2019.1628078

Accepted author version posted online: 10 Jun 2019.

Submit your article to this journal $\square$

View Crossmark data \lceil 


\section{Adapting Evidence-Based Practices to Improve Library Instruction:}

\section{Using customized tools to support peer mentoring and observation}

Short title: Using customized tools to support peer observation

$$
\begin{aligned}
& \text { Mary K. Oberlies } \\
& \text { Instruction \& Research Librarian at William \& Mary } \\
& \text { https://orcid.org/0000-0003-0822-1804 } \\
& \text { Kristin Buxton } \\
& \text { Science Librarian at University of Oregon } \\
& \frac{\text { https://orcid.org/0000-0002-1693-7039 }}{\text { Annie Zeidman-Karpinski }}
\end{aligned}
$$

The Kenneth M. and Kenda H. Singer Science Librarian at University of Oregon https://orcid.org/0000-0001-5409-2869

Corresponding author: annie@uoregon.edu 


\begin{abstract}
To improve the quality of our instruction, and to contribute to student success, we designed an instructional development program using peer mentoring and observation grounded in evidence-based practices. We identified three methods of peer observation and mentoring to create an innovative progressively in-depth program that helps librarians understand what is happening in the classroom, and works within a community of practice to identify ways to improve the quality of our instruction. These tools, used in higher education, were then customized to work for information literacy instruction: Teaching Squares, the Teaching Practices Inventory - Information Literacy Instruction, and the Classroom Observation Protocol for Information Literacy. These tools help librarians identify evidence-based practices, understand what occurred in their classrooms, and lead to student-focused teaching. This article discusses the development of these tools and initial findings.

\section{Introduction}

Although instruction is increasingly part of the work that librarians do, teaching librarians how to teach has not been widely adopted in MLIS/MLS programs, nor is that deficit uniformly remedied on the job (Carlozzi, 2018; Davies-Hoffman, Alvarez, Costello, \& Emerson, 2013; Julien \& Genuis, 2011; Saunders, 2015; Walter, 2005). As professionals, we aim to prepare resource rich classes, shape clear examples to demonstrate what instructors want covered, and the skills we know students need to be successful. Due to lack of time, an abundance of resources, and classroom constraints with space and technology, many of us find that we can cover the most ground by talking and demonstrating to students. However, by lecturing we are not leveraging the most effective practices for instruction. Broadly speaking, we are referring to what has been called high impact educational practices (Kuh, 2008), active-engagement instructional approaches (Smith, Jones, Gilbert, \& Wieman, 2013), inquiry based activities (Knight \& Wood, 2005), evidence-based practices (Adams, Gaffney, \& Lynn, 2016), scientific 
teaching (Handelsman, Miller, \& Pfund, 2007), increased course structure (Eddy \& Hogan, 2014), active learning (Freeman et al., 2014) and flipped classrooms (Arnold-Garza, 2014; Gross et al., 2015) to name a few of the most prevalent terms. For purposes of this paper, we will call all of these methods evidence-based practices.

We are not alone in needing to learn how to integrate these approaches into our teaching practice. Many faculty and instructors also need to change to accommodate new evidence about student learning and effective teaching. To help them with these changes, full time faculty and instructors have a culture of peer observation and evaluation that librarians typically do not. We suggest that we adopt programs that build communities of practice, and tools that articulate best practices for effective teaching, so we can form a culture of observation that is responsive to the needs of librarians and students. We can use mentoring and reflection to integrate new teaching methods, and to improve the effectiveness of our instruction (Bryan, Asher, \& Karshmer, 2018; Middleton, 2002; Snavely \& Dewald, 2011; Walter, 2005). Looking at the literature, we identified three tools that have been widely accepted and positively reviewed, Teaching Squares (TS), the Teaching Practices Inventory (TPI), and the Classroom Observation Protocol for Undergraduate STEM (COPUS). These tools use observation and reflection to evaluate teaching practices using data and value-neutral feedback. Considering the often solitary journey most instruction librarians travel - developing, revising, reflecting and refining our lessons in private - and, in our experience, concern about colleagues observing classes, neutral, data driven tools can help participants feel at greater ease with the process. We began testing these tools in our instruction and found the unique nature of singlesession information literacy instruction at times made them an awkward fit. To overcome this challenge we decided to customize them to meet the needs of instruction librarians.

Recently, as directed by our library's strategic plan, we established a program designed to incorporate current research on student success, evidence-based practices, and peer 
observation using these customized tools. We will describe why establishing a community of practice is relevant to librarians in our literature review. We then provide background on Teaching Squares, the Teaching Practices Inventory-Information Literacy Instruction, and the Classroom Observation Tool for Information Literacy, and how the program is implemented during an academic year. Finally, we describe early findings and data from the pilot. The ultimate goal is to improve the quality of instruction through peer mentoring ,documenting current instructional practices (observation), and reflection.

\section{Literature Review}

In designing a program geared toward improving teaching practices and creating a culture of collective learning and sharing, our task force wanted to ensure we selected tools to help librarians foster student success, gain a stronger understanding of evidence-based practices, and encourage a system of unbiased peer observation. By highlighting these three areas, we connect to a large body of work being conducted in other fields, and have found that the best practices delineated within this review are useful to what we do as instructors. We began with a review of literature to learn what others had discovered and investigate potential obstacles that we would need to address for our program to be successful.

\section{Student Success}

Enter any educational institution today and you will hear discussions about student success. We believe this is more than graduation and preparation for future careers, it is also about gaining the skills necessary to thrive and contribute in today's global society (Cuseo, 2009; Kuh, 2008). Through their education, students should demonstrate personal growth, selfdirection, and ethical, civic and intellectual development (Cuseo, 2009; Kuh, 2008). Librarians are uniquely placed to contribute to positive outcomes for students.

The Association of American Colleges and Universities (AAC\&U) identified ten highimpact practices (Kuh, 2008). These practices create opportunities for students to synthesize what they learn in the classroom in different settings, both on and off campus, and to apply their 
knowledge in more meaningful ways. By participating in multiple high-impact activities during their undergraduate years, students are more likely to be engaged, and therefore, succeed (Cuseo, 2009; Kuh, 2008; Oakleaf, 2010). Two of these practices, active and collaborative learning and undergraduate research, have been found to be especially beneficial to students . They have consistently significant, positive effects on outcomes like critical thinking, cognition, and moral reasoning (Kilgo, Ezell Sheets, \& Pascarella, 2015). Libraries can contribute meaningfully to student success through active and collaborative learning by engaging our students effectively during our time with them.

Current studies by academic librarians have largely considered two variables relating to student success: persistence (graduation or re-enrollment) and academic achievement (GPAs). When measuring student use of library services in relation to retention, studies have found a positive relationship between first year students who use the library at least once and higher GPAs and retention to the next semester (Murray, Ireland, \& Hackathorn, 2016; O'Kelly, 2017; Soria, Fransen, \& Nackerud, 2013). Receiving information literacy instruction in the form of workshops or one-shot instruction also appear to have a positive relationship with higher GPAs and persistence toward graduation or reenrollment (Wong and Cmor, 2011; O'Kelly, 2017; Bowles-Terry, 2012; and Gaha, Hinnefeld, and Pellegrino, 2018).

While evidence suggests that library use and information literacy instruction influences student persistence and achievement, student success requires creating a culture of learning through engagement. Walker and Pearce (2014) looked at student engagement and one-shot instruction and found there was no significant relationship between the two. This could be because a significant change is not truly possible in a 50-minute session, and information literacy instruction needs to be more pervasive through outreach, a scaffolded instruction program, and/or an information literacy requirement. Fisher (2018) challenges the exercise of tying student success and use of academic libraries. She builds a compelling case that students with more resources are also more likely to succeed in college and they are more likely to use 
libraries. Instead, Fisher encourages us to find answers to different questions. To paraphrase, are we providing the right services, and the right information, to classes in our one-shot sessions (Fisher, 2018)?

Beyond examining student achievement and persistence to measure the impact of academic libraries on student success, libraries can encourage instructional development that supports the most vulnerable students. Organized, clear instruction positively influences student persistence for all learners; supporting librarian development to enhance teaching and instructional effectiveness could benefit students who need it most (Pascarella, Salisbury, \& Blaich, 2011). A positive impact on student achievement exists when teachers have mentors, and are encouraged to collaborate, create communities of practice, and engage in continual learning (Darling-Hammond, 2008; Ross, 1992). Student success is amplified by teacher development. Librarians and teachers can both benefit by having paths to learn about and implement best practices.

\section{Evidence-Based Practices}

In healthcare, the highest and best standard of care is the use of evidence-based practices (EBP). Patients are diagnosed and treated based on the integration of research, education of the health care providers, clinical experience and patient preferences (Sackett, 2000). In education, similar efforts have been made to integrate research, education and practice. Using EBP in instruction generally refers to using a practice that has been shown to be more effective than methods the instructor was previously using (Mayer, 2008).

Planning for academic instruction is generally done autonomously and active learning is considered to be a choice, and not necessarily the most effective option in the classroom. While it is clear from the literature that all students learn more and retain more from classes that are not only lecture, there are many ways to teach using EBP (Arnold-Garza, 2014; Dabbour, 1997; Eddy \& Hogan, 2014; Freeman et al., 2014; Freeman, Haak, \& Wenderoth, 2011; Gross et al., 2015; Knight \& Wood, 2005). Depending on the librarian, the subject matter, the instructor 
requesting the session, as well as any number of other factors, it may be appropriate to use active learning, flipped classrooms, principles of critical pedagogy, problem based learning, or a combination of these and other options (Gross et al., 2015; Haak, HilleRisLambers, Pitre, \& Freeman, 2011; Williams, 2001; Young \& Maley, 2018). Engaging the students and giving them a structured class where they have the chance to practice the skills and tools that we want them to use is vital.

\section{Peer Observation}

Peer observation has a long history in higher education, but only recently has it been adopted by academic libraries (Middleton, 2002). It can be used as either a summative or formative process. When practiced in a summative manner, evaluations are used for promotion, tenure, or retention decisions and are generally formal programs sponsored by library administration (Middleton, 2002; Snavely \& Dewald, 2011). In a formative mode it may be formal or informal, voluntary, and intended as a reflective practice to improve instruction (Hultman Özek, Edgren, \& Jandér, 2012; Levene \& Frank, 1993). Formative practice tends to be nonevaluative and involve observation by peers rather than by those higher in rank or seniority (Levene \& Frank, 1993). It also can happen more frequently and spontaneously, rather than on a formal cycle, and it aims to facilitate growth (Vidmar, 2006).

Many peer observation programs build in a series of meetings to establish trust, identify teaching goals before the class observation, and provide time for reflection afterwards (Alabi et al., 2012; Alabi \& Weare, 2014; Levene \& Frank, 1993; Samson \& McCrea, 2008; Vidmar, 2006). The pre-observation meeting helps set context and ground rules for the observations. Planning for the pre-observation meeting tends to provide more formal structure so that the observed must define the class more clearly (Alabi et al., 2012).

Both the observer and observed reap the benefits of participation (Martin \& Double, 1998; Mueller \& Schroeder, 2018). Observers, experienced, as well as newer teachers, get ideas for teaching techniques and approaches they can apply (Alabi et al., 2012; Middleton, 
2002; Samson \& McCrea, 2008). Those observed can get feedback on practical details, strategies, and a partial glimpse into how the class might be received by students. Both the observer and observed benefit from developing a support network around teaching (Alabi et al., 2012; Hultman Özek et al., 2012; Sinkinson, 2011).

The most common challenge for peer observation programs relates to their voluntary nature, time constraints for the participants, and discomfort with the level of self-reflection needed (Alabi et al., 2012; Sinkinson, 2011). Attempts to focus and reflect on our instruction by using tools like the ones we describe here are worth overcoming those barriers, as they provide a chance to consider what the users of our libraries need. Meaningful change will take time and resources as well as conscious effort. We feel that potential impact to make our lessons more effective for the most vulnerable students is well worth the work it will take to make changes.

\section{Background Information on Evaluation Tools}

A task force of seven librarians conducted a literature review of classroom observation tools used in higher education to identify methods for measuring instruction that could work for our program. One report we read documented the work of twenty-two experts who reviewed nine observation tools used in higher education (William T. Grant Foundation, Spencer Foundation, \& Bill \& Melinda Gates Foundation, 2014). Three of us tested several options on each other during one-shot sessions held in Spring 2018 to determine how easy it was to use the tools and if the data gathered helped us understand classroom practices. Based on this pilot project and the training that one of the librarians has received with science faculty, we found two nationally calibrated tools, the Teaching Practices Inventory (TPI) and the Classroom Observation Protocol for Undergraduate STEM (COPUS), proved the most useful, once we modified them for information literacy and our one-shot sessions. We also identified a peer mentoring tool, Teaching Squares (TS), used with great success by one of us in a different library, which creates communities of practice and encourages reflection and growth. These 
tools measure the use of high impact, evidence-based practices and the types of activities happening in the classroom.

\section{Teaching Squares}

Developed by Anne Wessely at Stonehill College (Haave, 2014), TS is a non-evaluative program that builds small communities of practice through peer observation, learning, and selfreflection. The program allows librarians to gain new insights into their teaching and the teaching of others. TS creates a low stress and supportive environment to start reflecting on personal instruction goals and provides colleagues a chance to support those efforts. The four librarians in each "teaching square" agree to visit each other's classes over the course of a semester, meet occasionally to discuss areas of interest, and plan a final sharing meeting to discuss what they learned from their observations. The observing librarian uses a double-entry form to document what occurred during a session and their personal reflections on what they see. At the start of a TS each member establishes at least one teaching goal they would like help achieving. Goals have included integrating a new evidence-based practice into instruction, work on fine tuning time management for a class, how to best organize concepts, improving clarity of language and avoiding filler words. The goal of the TS program is to encourage personal self-reflection, not peer evaluation. The formal process of preparing, observing and debriefing will be described in more detail below. However, conversations within the Square focus on what individuals learned about their own teaching from observing others. It embraces the ethos of celebrating and appreciating the work of colleagues, reflecting on observations, and considering how to apply the observation to personal instructional growth.

\section{Teaching Practices Inventory}

The TPI was developed by Carl Wieman and Sarah Gilbert to quantify the teaching practices used by science, technology, engineering, and mathematics (STEM) instructors (Wieman, Gilbert, \& Dolan, 2014). They created the inventory based on prior research of effective teaching practices for STEM courses. The inventory consists of 72 items an instructor 
might include in a course. Each item has a point value assigned according to its efficacy based on evidence in the literature. For individual instructors, TPI can provide a list of practices they are already using, high impact activities they might want to adopt, and a method to quantify changes in their teaching over time. The TPI helps with reflective teaching practices, inspiring innovation in classroom sessions. It is designed to give instructors a clear path to understanding, and then using, best practices in their classes.

\section{Classroom Observation Protocol for Undergraduate STEM}

The COPUS was developed as a structured tool to provide information to a STEM instructor about how time is spent in class, recording in a non-judgmental way what the instructor and students are doing (Smith et al., 2013). After a relatively brief training (approximately 2 hours) an observer records what is happening in the class every two minutes based on a list of 25 codes, many of which include best practices for evidence-based activities. The tool does not consider the "quality of the teaching or the efficacy of student work" (Smith et al., 2013). The data generated from the process can be visualized and aggregated to determine how to focus professional development for a department, as well as compare practices at various scales (individual, departmental, and institutional). COPUS is particularly good at making information easy to share with a larger community, by making it possible to anonymize the information gathered in a session. It is also useful that the role of the observer, while present, is not a participant. Their role is to note what is happening for both the instructors and students and put it in one of the predetermined categories. Questions about how to code the action in a classroom should be addressed in the training and the observers should have clear consensus about what goes where on the instrument. COPUS was designed to incorporate the best of other tools developed to document instructional practices and capture student behavior.

\section{Modifying the Tools}

We wanted to take advantage of tools developed for other disciplines that had been proven effective, but found that they did not necessarily work for librarians teaching one-shot 
sessions. Librarians often go into the classroom only once and try to cover content that is either requested by the course instructor or perceived by the librarian to be vital to student success. To ensure the tools were effective for our purposes, they were modified to meet the needs of librarians teaching IL sessions. The modifications ranged from clarifying language about group activities, including additional evidence-based practices like rapport building, and considering what to do with entries for quizzes and exams.

\section{Teaching Practices Inventory - Information Literacy Instruction}

Initially, we tried to use the TPI as originally published, but found that much of the inventory was geared towards instructors teaching term-long credit courses. We decided to create a modified version, Teaching Practices Inventory-Information Literacy Instruction (TPI$(L I)^{1}$, specifically aimed at librarian instructors. While we left much of the inventory alone, we did make changes in multiple areas. We changed the focus from a full term class to a single session and rearranged the items to fall into pre-class, during class, and post-class activities. We also clarified the roles of the course instructor and librarian since they are treated in the original TPI to be the same person. We also added library-specific items such as providing a LibGuide or other electronic resources to the students.

\section{Classroom Observation Protocol for Information Literacy}

After selecting COPUS as one of the peer observation tools, we initially planned to use it without modification. COPUS had been successfully used by one of the authors for observation of several librarian colleagues. As we started to roll out the program to more librarians, questions arose about some of the observation codes. As a result, we decided to streamline categories, clarify the keys to many of the codes for our context, and add a few IL specific codes. For the codes identifying student activity, we combined codes WG (Worksheet group work) and OG (Other group work) into one code WG (Group work) and added code IA

\footnotetext{
${ }^{1}$ The TPI-ILI with citations of literature documenting these evidence-based practices is available at: https://tinyurl.com/yyxh7rdg
} 
(Individual work). For the instructor activity codes, we added codes RB (Rapport building) and P (Pausing). A key to the observation codes is available in the Appendix. We did not change the overall mechanics of how the 2 minute observations work, although we added rows for the minutes before class formally starts. We named our new version Classroom Observation Protocol for Information Literacy (COPIL).

\section{Implementing the Program}

During this program, librarians use the TS, TPI-ILI, and COPIL tools to understand classroom events, opportunities for innovation, and use of high impact evidence-based practices. The variety of data collected allows librarian-instructors to put theory into practice and recognize progress in teaching during participation in the program. Implementation starts with planning and sharing information about each leg of the program with librarians. Transparency and communication is key to launching the program. We know of no other equivalent program currently in use for IL or for the one-off class sessions that most librarians teach on a regular basis.

Overall, these tools and programs help develop a culture of learning through observation and reflection to improve teaching practices. COPIL and TPI-ILI collect data about what the librarian and students are doing in the classroom during the observation. Documenting current practices and reflecting on benefits and desired teaching improvement are important aspects of instruction. Since peer observation exists in both the TS and COPIL, they can be stand-alone programs, but either should be used in conjunction with the TPI-ILI. Due to the different strengths of these tools, we recommend splitting librarians into different cohorts and alternating between TS and COPIL (ex. year 1 group A participates in TS, and group B in COPIL; and in year 2 group A participates in COPIL and group B in TS). The TPI-ILI can be used with either program, and while we do not recommend it as a standalone, due to the absence of peer observation and feedback, we can see using it with other IL trainings because of how it documents our work, and constitutes part of a reflective practice. . 
Librarians were invited to participate in the program, which ran through the academic year. At the end of the year, participants were encouraged to report on their experiences, consider the benefits from participating in the program, and how it impacted their instruction. The reporting was done privately and at instruction workshops and meetings. We hope that the more information is shared, others will be interested in participating next time. Implementing the program is fairly easy, but does require designated individuals to coordinate the work. We had a group of six librarians coordinate the program during our pilot phase (two people per tool). We drafted an implementation timeline ${ }^{2}$ to guide our work and shared it with participants so they would know what was expected of them.

\section{Teaching Squares}

When assigning members to squares the following aspects should be taken into consideration:

- Subject expertise: Consider a blend of subject areas so participants can see a wider spectrum of skills and methods.

- Years of experience: When possible ensure participants have a mixture of experience. The best scenario is to ensure each square has two experienced members and two developing members. No square should be made up of only new librarians.

- Social Networks: When possible try to place individuals into groupings where they will have an opportunity to work with people other than their usual collaborators. For example, blend librarians from other campus libraries, departments, etc. Take care to consider any potential tensions between individuals. The square membership should be harmonious and nurturing.

\footnotetext{
${ }^{2}$ The University of Oregon academic calendar works on a quarter system. Our implementation timeline follows this system: https://tinyurl.com/y4qdljeg
} 
- Teaching Methods: Mixing square membership to include individuals who use different teaching methods can provide a broader array of experiences. For example, those who prefer lecture styles should be grouped with those who like active learning.

After assigning individuals to squares, participants should have the opportunity to identify possible issues with square assignments. Participants are provided with the Teaching Squares Manual, ${ }^{3}$ which outlines expectations and the tools participants need for observations and reflections. We recommend holding a TS orientation to answer any questions and provide the members of the squares an opportunity to meet each other and begin their work.

TS operated during the first half of the academic year. Each member established goals for the term, observed one another, reflected on their observed instruction sessions, and reflected on their experience in the square. It is recommended that the TPI-ILI is completed for each observed instruction session for comparison with the double-entry observation form. At the conclusion of the program, members had a final meeting to share their experiences and provide feedback on the process.

\section{Teaching Practices Inventory - Information Literacy Instruction}

The inventory provides librarians a chance to document their preparation for instruction and their actual teaching practices in the class session. This tool also can help librarians think of new ideas for instructional practices. The TPI-ILI is completed independently by the teaching librarian prior to receiving the double-entry observation form (TS) or COPIL sheets from the observing librarian. The TPI-ILI can be completed as a paper document or submitted electronically. ${ }^{4}$

The general purpose of the TPI-ILI is to identify which evidence-based practices are being used by the librarian and to provide a comparison between their perceptions of the

\footnotetext{
${ }^{3}$ Access our Teaching Squares Manual at: https://tinyurl.com/yyqc8hxh

${ }^{4}$ Access to the TPI-ILI was made available as a Qualtrics form, which provides a report of responses for the librarian after they submit the form. Access our form at: https://tinyurl.com/y4nomdah
} 
teaching session and the peer observers' perceptions. For example, during teaching, the librarian might estimate that $50 \%$ of the session was active learning, but the COPIL might show evidence of more/less active learning. This information can help the teaching librarian better assess their instructional practices.

As part of this program, each participating librarian completes two TPI-ILI forms, one each for TS and COPIL. At the end of the academic year, the librarian will be able to compare the practices they used in the classroom from the start of the year to the end of the year. Given the pace of an academic cycle, using this tool over longer periods of time will also be beneficial, because teaching practices may take some time to change.

\section{Classroom Observation Protocol for Information Literacy}

COPIL allows observers to reliably characterize how librarians and students are spending their time during the instruction session. The observer documents what the students and teaching librarian are doing using specific observation codes and timed observations. Behaviors listed in the code sheet include typical classroom activities, interactive activities, and non-instructional activities as well as evidence-based practices. The observation spreadsheet ${ }^{5}$ creates graphs that provide visual representations of how time was spent in the classroom, including the percentage of time spent conducting specific activities.

COPIL observers require training to accurately complete the observation matrix consistently with other observers. The COPIL training ${ }^{6}$ takes about 2 hours and consists of watching instructional videos and repeatedly completing the COPIL observation matrix, discussing findings, and comparing scores with others in the training. By the conclusion of the training, the observers should understand how each code is used so they can document the same information from observation to observation. A cohort of observers should be identified and trained on COPIL before the start of the second half of the academic year.

\footnotetext{
5 Excel template available at: https://tinyurl.com/y2st58mj

${ }^{6}$ Information about the training is available at: https://tinyurl.com/y45jsgy8
} 
For our program, we asked librarians who participate in TS to complete a COPIL observation in the spring. In preparation for a COPIL observation, the person being observed and the observer should have a pre-instruction meeting to discuss the class, lesson plan, and instructional goals. Following the observation, the teaching librarian should complete the TPI-ILI and post-instruction reflection ${ }^{7}$ and then arrange a meeting with the observer. The teaching librarian should note any differences between their two TPI-ILI results (TS session and COPIL session), reflections, and their teaching goals to measure change/growth. During the postinstruction meeting, the observer and the person observed will review the COPIL codesheet and graphs, and complete the COPIL and TPI-ILI follow-up reflection document.

Some questions in the TS document and COPIL reflection overlap. The intention behind this repetition is to encourage reflection as normal habit after teaching. The COPIL reflection template contains pre-instruction and post-instruction interview questions, which encourage librarians to compare their teaching plan, the actual events of the class, and ideas for future instruction.

All of the information gathered in this program, TS, TPI-ILI and COPIL, is confidential and for the sole use of the observed librarian. If desired, the librarian can use the observations to document their work, goals and growth for contract renewals, promotions, or anything else that they choose. While we are not tenure-track faculty at our libraries, this is a tool modified from one used for tenured instructors from other disciplines and may be of particular interest to librarians who include instruction evaluations in their tenure files.

\section{Data \& Early Findings}

Prior to recruiting the first cohort for the program, three librarians tested each tool to determine its effectiveness for instructional development. The data provided here documents the practices of two librarians who participated in the early test. Additional librarians have since used all of the tools and their overall impressions will be shared. Both of the classes observed

\footnotetext{
${ }^{7}$ A copy of our post-instruction reflection template is available at: https://tinyurl.com/yywt7f4p
} 
here include significant hands on work for the students, with the teaching librarian serving primarily to introduce the activities and guide the students. One of the benefits of looking at the data visualized in this way is that librarians can easily see the overall pace and structure of their sessions with "Occurance of activity..." figures. What is striking in the figures showing "Frequency of activities..." is how plainly one can see that when librarians are guiding, the students are working and/or answering questions. Conversely if the librarian is lecturing then students are receiving.

\section{COPIL and TPI-ILI}

Librarian 1 taught an upper level writing course at the start of the Fall 2018 term. The session provided students with an introduction to the library and conducting research in Web of Science through a game-based activity. The course was an elective, science-focused, interdisciplinary writing course for upper-level undergraduates.

Librarian 2 taught a First-Year Interest Group (FIG) in the Fall 2018 term. Students completed an activity to learn how to synthesize information for research projects and locate information in an integrated search tool (Primo) and a database. Students were freshmen taking a required class for the FIG.

Both sessions were observed using COPIL. Following the instruction, the teaching librarians completed the TPI-ILI and met with the observing librarian to complete the COPIL/TPIILI Reflection. COPIL was completed using an Excel spreadsheet which had been set up to graph the data into charts to show percentage of activities, percentage of time intervals, and activities across time. In these graphs, activities completed by students and instructors are grouped into broader descriptive categories to better highlight the type of activity being observed. These categories with associated activity are:

Student Activity Categories:

- Receiving: L

- $\quad$ Talking to Class: AnQ, SQ, WC, SP 
- Working: Ind, CG, WG, TQ, IA, Prd

- Other (Student): W, O

Instructor Activity Categories:

- Presenting: Lec, D/V, RtW

- Guiding: FUp, PQ, CQ, AnQ, MG, 101

- Admin: Adm, W

- Other (Instructor): RB, P, O

\section{Interpreting COPIL Data}

Librarian 1's IL session ran for approximately sixty-four minutes. Figure 1 provides a graphical output of the activities grouped by category that occurred during the first sixteen minutes of the session in two minute intervals. This graph provides insight into the overall flow of the class. It can be further broken down to show the precise activities that occurred over the course of the session for a more in-depth view (Figure 2). The graphs document that the beginning of class time was spent on discussion and group work with the instructor guiding. In terms of flow, they show the instructor setting up students for group work, guiding them through it, and then reconvening students for reflection. ${ }^{8}$

\footnotetext{
${ }^{8}$ Complete graphs and spreadsheet for whole class session available at: https://tinyurl.com/y3ctx9tv
} 
Occurrence of Activity by Time (Collapsed Codes)*

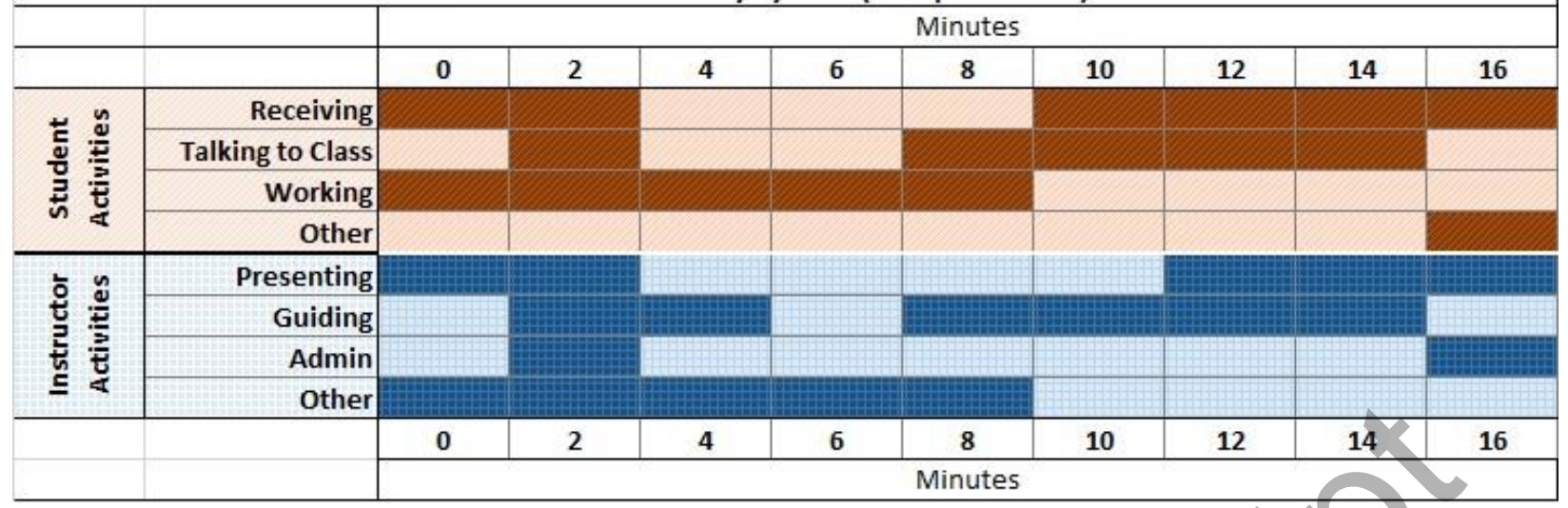

Figure 1. Activity by students and Librarian 1 grouped into activity type categories ( 2 minute intervals).

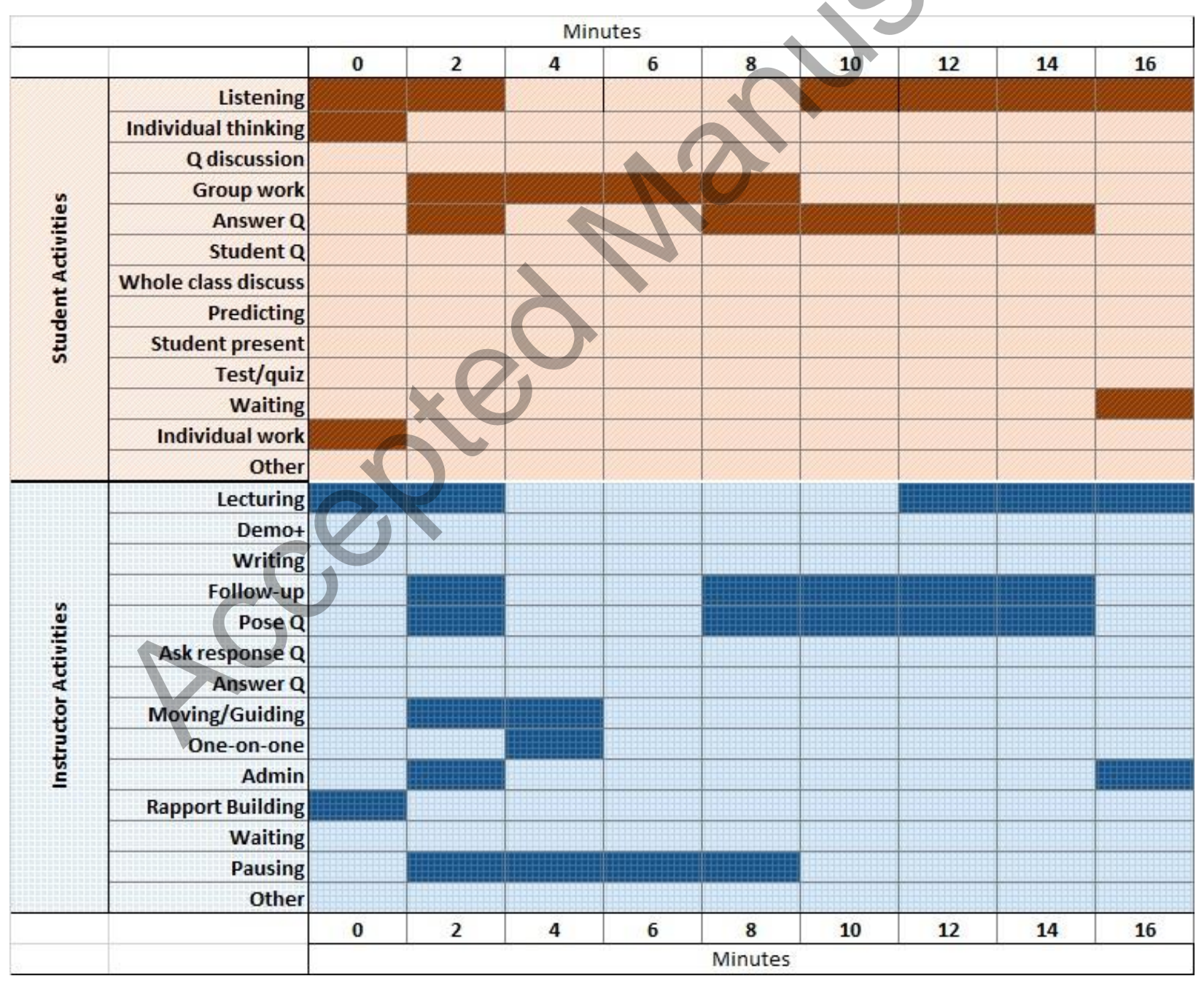

Figure 2. Activity by students and Librarian 1 by time (2 minute intervals). 
Figure 3 graphs how frequently a given activity code was marked compared to the sum of all codes marked in all time intervals during the class session and expresses the frequency as a percentage. From this graph, the librarian sees how often they engaged in a particular activity, rather than the percentage of time spent on that activity. This visualization is particularly helpful since multiple activities can occur during each two minute interval. The majority of the session was spent with students engaging in some type of activity (44\%) or engaged in discussion (34\%) with the instructor (Librarian 1) moving through the classroom checking in on work and answering questions (70\%). The other predominant instruction activities were conducting one-on-one interactions (30\%); moving through the classroom (21\%); and lecturing, pausing or following-up on activities (10/10/10\%). Students spent the majority of the session conducting group work (42\%).

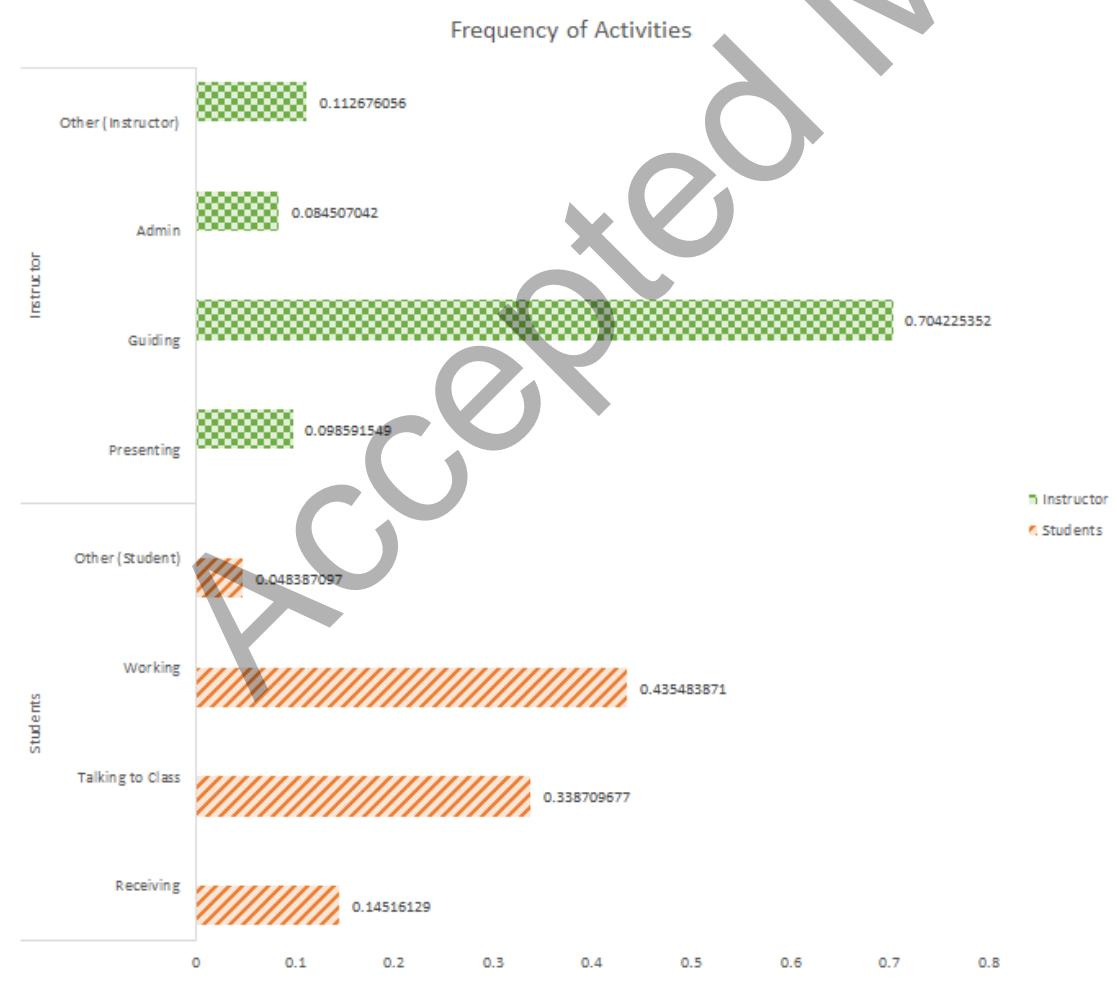

Figure 3. Frequency of activities by students and Librarian 1. 
Librarian 1 also completed the TPI-ILI following the instruction session. Evidence-based instruction practices in the planning and execution of the session included establishing a relationship with the faculty member to review the syllabus and plan IL activities; small group work and discussions; a hands-on activity; guided learning activities; and a reflection at the end of class. The majority of class time (82\%) was spent with students working on active learning activities.

Librarian 2's IL session ran for roughly forty-eight minutes. Figure 4 provides a graphical representation of the activities, grouped by category that occurred in the first sixteen minutes of the session in two minute intervals. Figure 5 shows a more in depth view by activity during this time. The graphs document that the beginning of the class time was spent on discussion and group work with the instructor guiding. In terms of flow of the class, the graphs show the instructor scaffolding the activities, pausing between each activity to bring the class back together for discussion, and ending with students presenting findings and the librarian providing feedback. ${ }^{9}$

\begin{tabular}{|c|c|c|c|c|c|c|c|c|c|c|}
\hline \multicolumn{11}{|c|}{ Occurrence of Activity by Time (Collapsed Codes) ${ }^{*}$} \\
\hline & & & & & & inut & & & & \\
\hline & & 0 & 2 & 4 & 6 & 8 & 10 & 12 & 14 & 16 \\
\hline \multirow{4}{*}{ 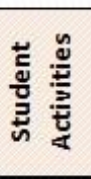 } & Receiving & & & & & & & & & \\
\hline & Talking to Class & & & & & & & & & \\
\hline & Working & & & & & & & & & \\
\hline & Other & & & & & & & & & \\
\hline \multirow{4}{*}{ 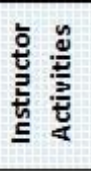 } & Presenting & & & & & & & & & \\
\hline & Guiding & & & & & & & & & \\
\hline & Admin & & & & & & & & & \\
\hline & other & & & & & & & & & \\
\hline & & 0 & 2 & 4 & 6 & 8 & 10 & 12 & 14 & 16 \\
\hline
\end{tabular}

Figure 4. Activity by students and Librarian 2 grouped into activity type categories (2 minute intervals).

\footnotetext{
${ }^{9}$ Complete graphs and spreadsheet for whole class session available at: https://tinyurl.com/yy4tz2ah
} 


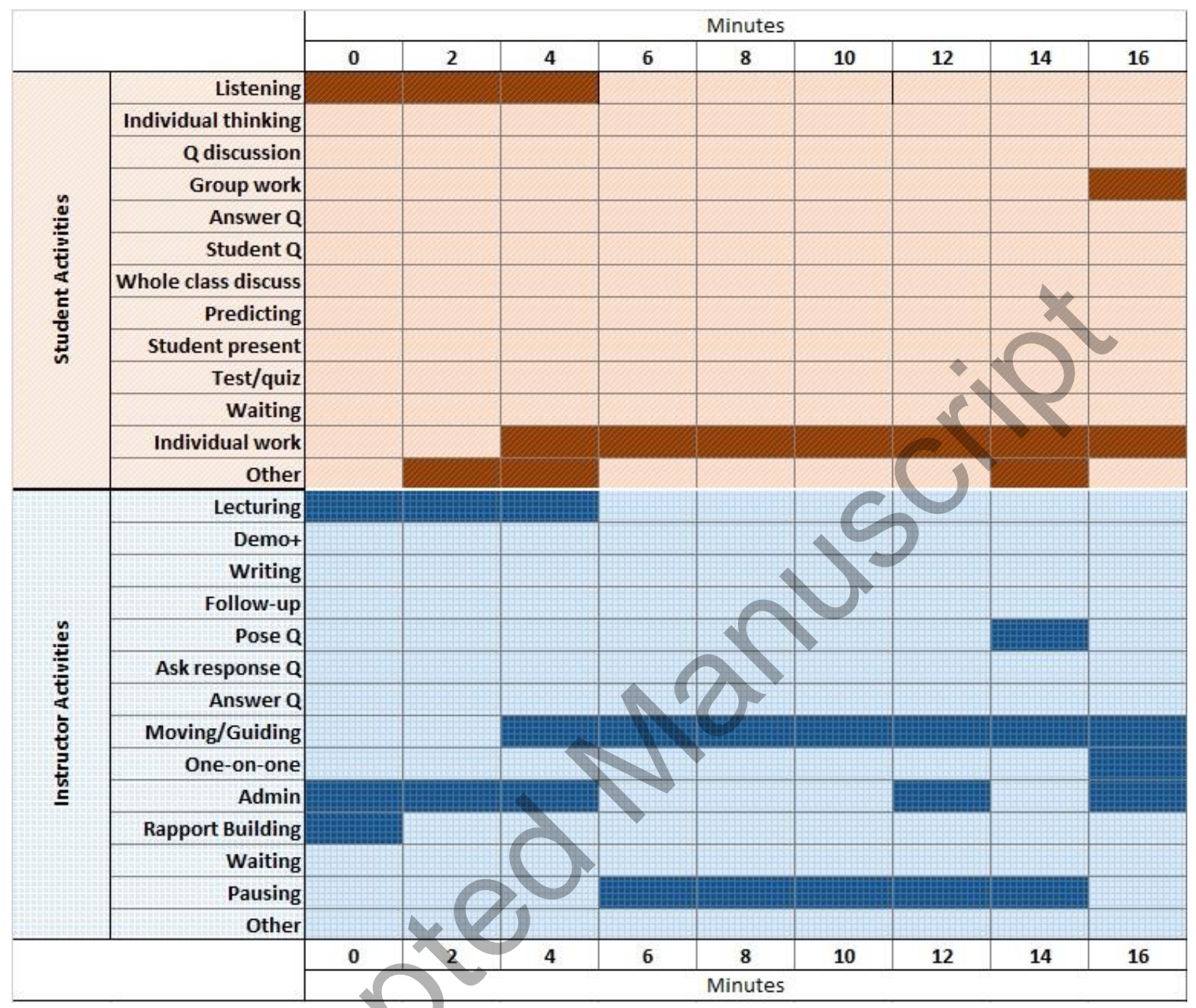

Figure 5. Activity by students and Librarian 2 by time ( 2 minute intervals).

Figure 6 graphs how frequently a given activity code was marked compared to the sum of all codes marked in all time intervals during the class session and expresses it as a percentage. The majority of the session was spent with students engaging in some type of activity (43\%) and the instructor moving through the classroom checking on work and answering questions (43\%). Librarian 2 spent the other half of session doing administrative work (setting up the next activity/explaining the activity) (22\%) or lecturing before/after the activities (19\%). Students spent most of the time conducting individual work (29\%). 


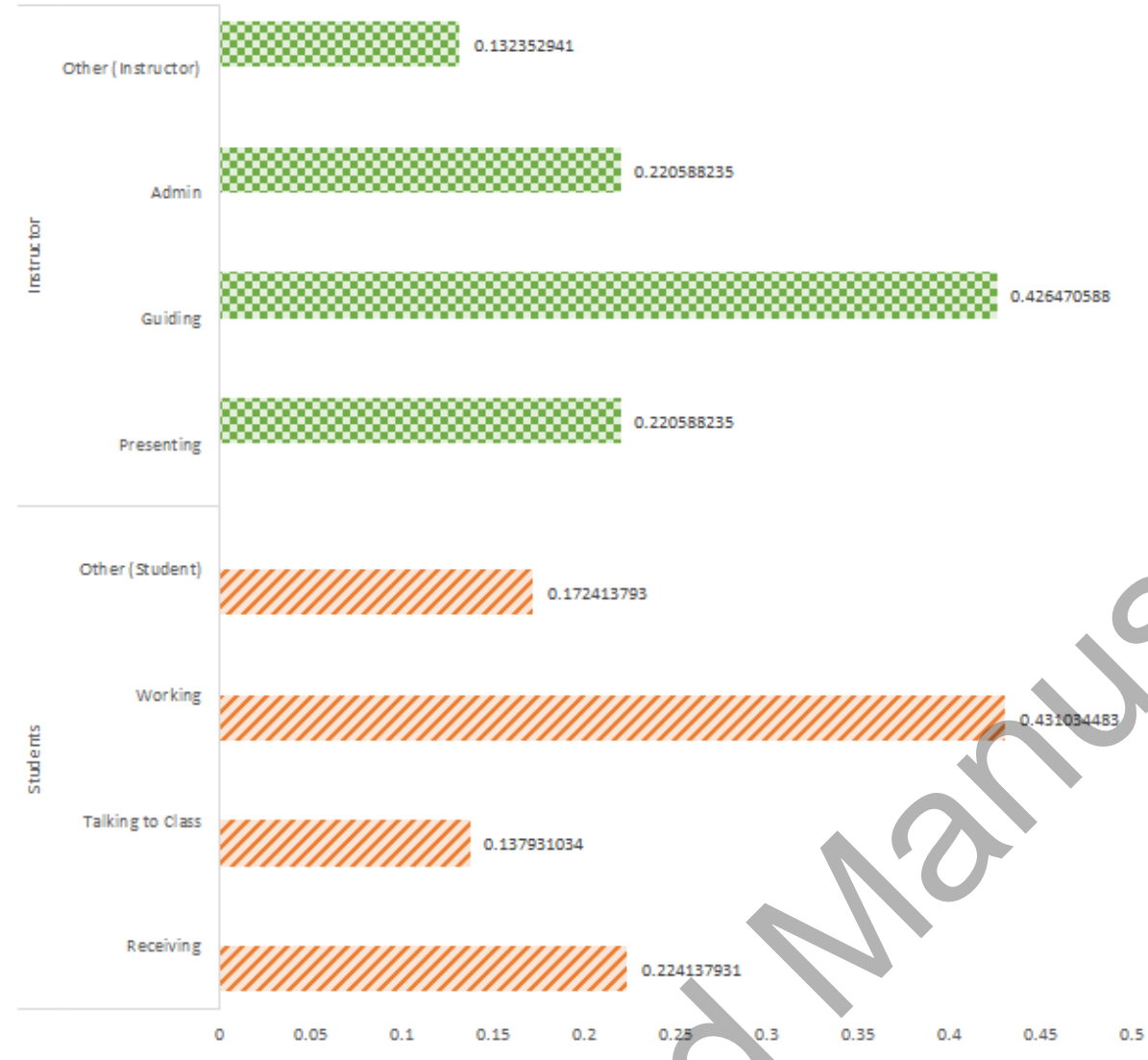

Figure 6. Frequency of activities by students and Librarian 2.

For Librarian 2 the TPI-ILI included the following evidence-based instructional practices: working with the instructor to develop the session activities; providing students with scholarly literature and examples to help students work through the session activities; and discussing with the instructor the students' perspective on the usefulness of materials. Students were asked to review materials before the class session. During class, students worked individually and in groups on librarian-assigned activities, reflected on the activity they conducted, and generated ideas about how they would apply activities in the future.

In addition to going over the COPIL graphs and TPI-ILI data during the reflection session, the observing librarian provides positive feedback on the instruction session as well as recommendations for future instruction. These recommendations are intended to help the 
teaching librarian increase the use of evidence-based teaching methods and create the best learning outcomes. These recommendations can be used as teaching goals when working within a TS.

Since Spring 2019, seven librarians have been observed using COPIL. Each found that it helped them understand how they, and their students, used their time during instruction. The majority of these librarians stated that the observation helped them identify areas in their teaching to adjust and plan to change in the future. Overall, participants found COPIL indicated ways for them to engage in reflective practices, identify strengths and weaknesses in their teaching, and helped them consider areas of change.

\section{Teaching Squares}

The authors participated in a pilot TS in Spring 2018. When asked about the experience, one author said they benefited from both observing and being observed. As an observer, they learned a teaching activity they had not seen previously (and was able to acquire a handout for later use) and appreciated seeing how the other two authors managed time and structured their

classes. When they were observed, they received confirmation that recent work they had done to improve an activity had made it clearer.

The formal TS program launched in Fall 2018 with two Squares (eight participants) that ran through March 2019. Observations have been completed and the Squares have reflected on the experience. Most of the participants found the experience productive and useful. Some librarians even requested critical feedback, providing evidence these communities are considered safe, mutually supportive spaces.

\section{Discussion}

As we have started the formal program, the tools have generally worked as intended. The problems we faced included ensuring that all participants understand the process and having limited institutional support. 
Since the programs are new, there has been some confusion among participants about what to do when. When exactly to fill out which observation forms, when to meet after an observation to fill in the reflection tools, and when to do TPI-ILI in relation to the observed sessions were common concerns. With familiarity and possibly a new checklist, we believe these difficulties will largely resolve. Scheduling has also been a challenge for conducting the observations, including setting aside time to meet before and after the observation. One of the lessons we have learned from this pilot is the importance of reflecting shortly after the observations have occurred, and then having the Squares meet and discuss the sessions. Using the reflection template to add context to the COPIL scores and TPI-ILI is essential for seeing what our current practice looks like and deciding what to do next.

Our program has been entirely voluntary. Of the approximately 22 librarians who could have participated, we had eight participate in TS, and four who volunteered to be trained to observe using COPIL. The voluntary nature, narrow uptake of the programs, and some change in personnel have constrained the benefits to the teaching program as a whole. At other libraries, where TS has been mandatory, the benefits have been more widespread. In order for a peer-mentoring and observation program like this to work, instruction programs will need administrative support. While these programs do not require big investments, they flourish with encouragement (Bathgate, et al 2019). The commitment to using the tools we describe here is not inconsequential. However, the rewards are significant as these programs build community and provide support to improve instruction for all skill levels. When we asked participants about their experiences within their Square and having a COPIL observation they shared that the tools had positively impacted their instruction and encouraged them to reflect on their practices.

In the future, we look forward to benefiting from the ongoing efforts to map a five-step EBP model to the ACRL Standards as well as the ACRL Framework for Information Literacy in Higher Education (Adams, 2014; Adams et al., 2016; Franzen \& Bannon, 2016; Young \& Maley, 2018). These steps involve teaching the information literate student to Ask-Acquire-Appraise- 
Apply and finally Assess what they found (Adams, 2014). The ACRL Framework is particularly well aligned to the EBP process, as it requires critical thinking and the careful consideration of the quality and applicability of the evidence found (Franzen \& Bannon, 2016). This is an area that would benefit from additional research, but is outside of the scope of this article.

\section{Conclusion and Next Steps}

We have tested these tools internally, but have not found another library ready to use TPI-ILI and COPIL themselves. We are interested in partnering with other libraries to help these instruments be robust enough to use in a variety of IL settings. Ultimately, the libraries who use these tools will need to understand and support them. An important aspect is to present the information and then understand if the tools meet the needs of the librarians who are teaching. We know that additional work is needed to fine-tune the COPIL codes. Our early tests have found the new codes an improvement, but we have also discovered some of the codes need clarification to ensure that all of the observers are clear about how to mark their observations. As a group, observers will need to reach consensus about what category is appropriate for contested activities. For example, we found some differences about coding a single student completing an activity, or a small group of students having a one-on-one question with the teaching librarian. These activities do not fall clearly in specific categories based on the current descriptions. Norming is part of the training process and the tools will be more useful as we refine them.

It is worth noting that these tools can help identify goals and show areas of strength. The information from several classes can be anonymously aggregated. One can see where there are opportunities for training and where we are meeting our stated instruction goals. This could ultimately help libraries improve their instruction programs by providing more targeted professional development and delivery of information literacy skills. By establishing a community 
of engaged participants and by identifying strengths, instruction coordinators can connect librarians who want help with librarians who are already strong in an area.

We think that given the very practical use of these tools, that a workshop model to help others learn about this, get training, address concerns, refine as needed, and then use it at their libraries would be helpful. We believe peer observation and constructive mentoring will allow librarians to become the best instructors they can be. We want this to be part of what we do as a profession. Letting other librarians know the value of mentoring from personal experience is one of the most effective ways to promote it. Hearing their concerns and incorporating their ideas, is equally important to help make the tools useful to others and make them more robust.

Originality statement

Some of the content of this article was presented in poster form at Library Instruction West 2018 and as a presentation at LOEX 2019, but this paper has not been published elsewhere nor has it been submitted anywhere else. 


\section{References}

Adams, N. E. (2014). A comparison of evidence-based practice and the ACRL information literacy standards: implications for information literacy practice. College \& Research Libraries, 75(2), 232-248.

Adams, N. E., Gaffney, M. A., \& Lynn, V. (2016). The Role of Evidence-Based Practice in Collaborations between Academic Librarians and Education Faculty. Portal: Libraries and the Academy, 16(4), 697-720. https://doi.org/10.1353/pla.2016.0048

Alabi, J., Huisman, R., Lacy, M., Miller, W., Snajdr, E., Trinoskey, J., \& Weare, W. H., Jr. (2012). By and for us: The development of a program for peer review of teaching by and for pretenure librarians. Collaborative Librarianship, 4(4), 165-174.

Alabi, J., \& Weare, W., Jr. (2014). Peer Review of Teaching: Best Practices for a NonProgrammatic Approach. Communications in Information Literacy, 8(2). https://doi.org/10.15760/comminfolit.2014.8.2.171

Arnold-Garza, S. (2014). The Flipped Classroom Teaching Model and Its Use for Information Literacy Instruction. Communications in Information Literacy, 8(1). https://doi.org/10.15760/comminfolit.2014.8.1.161

Bathgate, M. E., Aragón, O. R., Cavanagh, A. J., Waterhouse, J. K., Frederick, J., \& Graham, M. J. (2019). Perceived supports and evidence-based teaching in college STEM. International Journal of STEM Education, 6(1). https://doi.org/10.1186/s40594-019-01663

Bowles-Terry, M. (2012). Library Instruction and Academic Success: A mixed - methods assessment of a library instruction program. Evidence Based Library and Information Practice, 82-95.

Bryan, J. E., Asher, D., \& Karshmer, E. D. (2018). Assessing librarians' teaching of one-shot sessions: A new model for evaluating instructional performance. College \& Undergraduate Libraries, 25(4), 350-371.. 
https://doi.org/10.1080/10691316.2018.1527268

Carlozzi, M. (2018). Teaching in Libraries: Not an Elective Part of the Job. In J. Percell, L. C. Sarin, P. T. Jaeger, \& J. C. Bertot (Eds.), Advances in Librarianship (Vol. 44, pp. 201213). Emerald Publishing Limited. https://doi.org/10.1108/S0065-28302018000044B011

Cuseo, J. (2009). Student Success: Definition, Outcomes, Principles and Practices. Retrieved from https://www2.indstate.edu/studentsuccess/pdf/Defining\%20Student\%20Success.pdf

Dabbour, K. S. (1997). Applying active learning methods to the design of library instruction for a freshman seminar. College \& Research Libraries. https://doi.org/10.5860/crl.58.4.299

Darling-Hammond, L. (2008). Teacher Learning that Supports Student Learning. In Teaching for Intelligence (2nd edition, pp. 91-100). Thousand Oaks: Corwin Press.

Davies-Hoffman, K., Alvarez, B., Costello, M., \& Emerson, D. (2013). Keeping Pace with Information Literacy Instruction for the Real World: When Will MLS Programs Wake Up and Smell the LILACs? Comminfolit, $7(1), 9$. https://doi.org/10.15760/comminfolit.2013.7.1.131

Eddy, S. L., \& Hogan, K. A. (2014), Getting under the hood: How and for whom does increasing course structure work? CBE Life Sciences Education, 13(3), 453-468. https://doi.org/10.1187/cbe.14-03-0050

Fisher, Z. (2018, April 15). Who Succeeds in Higher Education? Questioning the Connection Between Academic Libraries \& Student Success. Retrieved December 9, 2018, from https://quickaskzoe.com/2018/04/15/who-succeeds-in-higher-education/

Franzen, S., \& Bannon, C. (2016). Merging Information Literacy and Evidence-Based Practice in an Undergraduate Health Sciences Curriculum Map. Communications in Information Literacy, 10(2). https://doi.org/10.15760/comminfolit.2016.10.2.26

Freeman, S., Eddy, S. L., McDonough, M., Smith, M. K., Okoroafor, N., Jordt, H., \& Wenderoth, M. P. (2014). Active learning increases student performance in science, engineering, 
and mathematics. Proceedings of the National Academy of Sciences. https://doi.org/10.1073/pnas.1319030111

Freeman, S., Haak, D., \& Wenderoth, M. P. (2011). Increased Course Structure Improves Performance in Introductory Biology. CBE-Life Sciences Education, 10(2), 175-186. https://doi.org/10.1187/cbe.10-08-0105

Gaha, U., Hinnefeld, S., \& Pellegrino, C. (2018). The Academic Library's Contribution to Student Success: Library Instruction and GPA. College \& Research Libraries, 79(6), 737-746. https://doi.org/10.5860/crl.79.6.737

Gawande, A. (2011). The Coach in the Operating Room. The New Yorker. Retrieved from https://www.newyorker.com/magazine/2011/10/03/personal-best

Gawande, A. (2017). Want to get great at something? Get a coach. Retrieved from https://www.ted.com/talks/atul_gawande_want_to_get_great_at_something_get_a_coac $\mathrm{h}$ ?language $=\mathrm{en}$

Gross, D., Pietri, E. S., Anderson, G., Moyano-Camihort, K., Graham, M. J., \& Ledbetter, M. L. (2015). Increased Preclass Preparation Underlies Student Outcome Improvement in the Flipped Classroom. CBE-Life Sciences Education, 14(4), ar36. https://doi.org/10.1187/cbe. 15-02-0040

Haak, D. C., HilleRisLambers, J., Pitre, E., \& Freeman, S. (2011). Increased Structure and Active Learning Reduce the Achievement Gap in Introductory Biology. Science, 332(6034), 1213-1216. https://doi.org/10.1126/science.1204820

Haave, N. (2014). Teaching Squares: A Teaching Development Tool. The Teaching Professor, 28(10), 1.

Haddow, G. (2013). Academic library use and student retention: a quantitative analysis. Library \& Information Science Research, 35(2), 127-136. https://doi.org/10.1016/j.lisr.2012.12.002

Handelsman, J., Miller, S., \& Pfund, C. (2007). Scientific Teaching. Macmillan. Retrieved from 
http://books.google.com/books?id=sufOMvxqoLQC

Hultman Özek, Y., Edgren, G., \& Jandér. (2012). Implementing the Critical Friend Method for Peer Feedback among Teaching Librarians in an Academic Setting. Evidence Based Library and Information Practice, 7(4), 68-80. https://doi.org/10.18438/B81C8W

Julien, H., \& Genuis, S. K. (2011). Librarians' experiences of the teaching role: A national survey of librarians. Library \& Information Science Research, 33(2), 103-111. https://doi.org/10.1016/j.lisr.2010.09.005

Kilgo, C. A., Ezell Sheets, J. K., \& Pascarella, E. T. (2015). The link between high-impact practices and student learning: some longitudinal evidence. Higher Education, 69(4), 509-525. https://doi.org/10.1007/s10734-014-9788-z

Knight, J. K., \& Wood, W. B. (2005). Teaching More by Lecturing Less. Cell Biology Education, 4(4), 298-310. https://doi.org/10.1187/05-06-0082

Kuh, G. D. (2008). High-Impact Educational Practices: What They Are, Who Has Access to Them, and Why They Matter. Washington, D.C: Association of American Colleges and Universities. Retrieved from https://provost.tufts.edu/celt/files/High-Impact-EdPractices1.pdf

Levene, L.-A., \& Frank, P. (1993). Peer Coaching: Professional Growth and Development for Instruction Librarians. Reference Services Review, 21(3), 35-42.

Martin, G. A., \& Double, J. M. (1998). Developing Higher Education Teaching Skills through Peer Observation and Collaborative Reflection. Innovations in Education and Training International, 35(2), 161-170.

Mayer, R. E. (2008). Applying the science of learning: Evidence-based principles for the design of multimedia instruction. The American Psychologist, 63(8), 760-769. https://doi.org/10.1037/0003-066X.63.8.760

Middleton, C. (2002). Evolution of Peer Evaluation of Library Instruction at Oregon State University Libraries. Portal: Libraries and the Academy, 2(1), 69-78. 
https://doi.org/10.1353/pla.2002.0019

Mueller, R., \& Schroeder, M. (2018). From Seeing to Doing: Examining the Impact of NonEvaluative Classroom Observation on Teaching Development. Innovative Higher Education, 43(5), 397-410. https://doi.org/10.1007/s10755-018-9436-0

Murray, A., Ireland, A., \& Hackathorn, J. (2016). The Value of Academic Libraries: Library Services as a Predictor of Student Retention. College \& Research Libraries, 77(5), 631641. https://doi.org/10.5860/crl.77.5.631

Oakleaf, M. (2010). The value of academic libraries: a comprehensive research review and report. Chicago, IL: Association of College and Research Libraries, American Library Association.

O'Kelly, M. (2017). Academic libraries and student retention: the implications for higher education. In Conference Proceedings (Vol. 7, pp. 485-490). Retrieved from https://scholarworks.gvsu.edu/library_proceedings/7

Pascarella, E. T., Salisbury, M. H., \& Blaich, C. (2011). Exposure to Effective Instruction and College Student Persistence: A Multi-Institutional Replication and Extension. Journal of College Student Development, 52(1), 4-19. https://doi.org/10.1353/csd.2011.0005

Ross, J. A. (1992). Teacher Efficacy and the Effects of Coaching on Student Achievement. Canadian Journal of Education / Revue Canadienne de l'éducation, 17(1), 51-65. https://doi.org/10.2307/1495395

Sackett, D. L. (2000). Evidence-based medicine: how to practice and teach EBM (2nd ed.). Edinburgh; New York: Churchill Livingstone.

Samson, S., \& McCrea, D. E. (2008). Using peer review to foster good teaching. Reference Services Review, 36(1), 61-70. https://doi.org/10.1108/00907320810852032 Saunders, L. (2015). Education for Instruction: A Review of LIS Instruction Syllabi. The Reference Librarian, 56(1), 1-21. https://doi.org/10.1080/02763877.2014.969392 Sinkinson, C. (2011). An assessment of peer coaching to drive professional development and 
reflective teaching. Communications in Information Literacy, 5(1), 9-20. https://doi.org/10.15760/comminfolit.2011.5.1.99

Smith, M. K., Jones, F. H. M., Gilbert, S. L., \& Wieman, C. E. (2013). The classroom observation protocol for undergraduate stem (COPUS): A new instrument to characterize university STEM classroom practices. CBE Life Sciences Education, 12(4), 618-627. https://doi.org/10.1187/cbe.13-08-0154

Snavely, L., \& Dewald, N. (2011). Developing and Implementing Peer Review of Academic Librarians' Teaching: An Overview and Case Report. The Journal of Academic Librarianship, 37(4), 343-351. https://doi.org/10.1016/j.acalib.2011.04.009

Soria, K. M., Fransen, J., \& Nackerud, S. (2013). Library Use and Undergraduate Student Outcomes: New Evidence for Students' Retention and Academic Success. Portal: Libraries and the Academy, 13(2), 147-164. https://doi.org/10.1353/pla.2013.0010

Vidmar, D. J. (2006). Reflective peer coaching: Crafting collaborative self-assessment in teaching. Research Strategies, 20(3), 135-148. https://doi.org/10.1016/j.resstr.2006.06.002

Walker, K. W., \& Pearce, M. (2014). Student Engagement in One-Shot Library Instruction. The Journal of Academic Librarianship, 40(3), 281-290. https://doi.org/10.1016/j.acalib.2014.04.004

Walter, S. (2005). Improving instruction: What librarians can learn from the study of college teaching. In H.A. Thompson (Ed.), Currents and convergence: Navigating the rivers of change: Proceedings of the twelfth national conference of the Association of College and Research Libraries, April 7-10, 2005, Minneapolis, MN (pp. 363-379). Chicago: Association of College \& Research libraries. Retrieved from: http://www.ala.org/acrl/sites/ala.org.acr/files/content/conferences/pdf/waltr05.pdf Wieman, C., Gilbert, S., \& Dolan, E. (2014). The Teaching Practices Inventory: A New Tool for Characterizing College and University Teaching in Mathematics and Science. CBE-Life 
Sciences Education, 13(3), 552-569. https://doi.org/10.1187/cbe.14-02-0023

William T. Grant Foundation, Spencer Foundation, \& Bill \& Melinda Gates Foundation. (2014). Measuring Instruction in Higher Education: A Summary of a Convening. Chicago, IL. Retrieved from https://wtgrantfoundation.org/library/uploads/2015/11/MeasuringInstruction-in-Higher-Education.pdf

Williams, B. (2001). Developing critical reflection for professional practice through problembased learning. Journal of Advanced Nursing, 34(1), 27-34.

Wong, S. H. R., \& Cmor, D. (2011). Measuring Association between Library Instruction and Graduation GPA. College \& Research Libraries, 72(5), 464-472. https://doi.org/10.5860/crl-151

Young, S., \& Maley, M. (2018). Using Practitioner-engaged Evidence Synthesis to Teach Research and Information Literacy Skills: A Model and Case Study. The Journal of Academic Librarianship, 44(2), 231-237. https://doi.org/10.1016/j.acalib.2018.02.002 


\section{Appendix}

\section{Key to COPIL Observation Codes}

\section{Classroom Observation Protocol for Information Literacy - COPIL ${ }^{1}$}

\section{Observation codes}

\section{Students are Doing}

L Listening to instructor/taking notes, etc.

Ind Individual thinking/problem solving. Only mark when an instructor explicitly asks students to think or write about question or another question/problem on their own.

CG Discussing an instructor question in groups of 2 or more students

WG Working in groups on an instructor assigned activity (i.e. worksheet, computer, jigsaw activity, etc.)

AnQ Student answering a question posed by the instructor with rest of class listening

SQ Student asks question

WC Engaged in whole class discussion by offering explanations, opinion, judgment, etc. to whole class, often facilitated by instructor

Prd Making a prediction about the outcome of demo or experiment

SP Presentation or demonstration by student(s)

TQ Test or quiz - unlikely

W Waiting (instructor late, working on fixing AV problems, instructor otherwise occupied, etc.)

IA Working individually on instructor assigned activity (i.e. students search on own computers, work on handout, etc)

o Other - explain in comments (i.e., have students passing things, collect things, moving stations)

\section{Instructor is Doing}

Lec Lecturing (presenting content, including PowerPoint, review pre-class assignment, etc.) [often checked along D/ ]

D/V Showing or conducting a demo, experiment, simulation, video, or animation

Rtw Real-time writing on board, doc. projector, etc. [often checked off along with Lec]

FUp. Follow-up/feedback on clicker question or activity to entire class

PQ Posing question to students (non-rhetorical)

CQ Asking a (survey, multiple choice, polling, etc) question where everyone has to respond [mark the entire time the instructor is using question, not just when first asked]

And Listening to and answering student questions with entire class listening

MG Moving through class guiding ongoing student work during active learning task

101 One-on-one extended discussion with one or a few individuals, not paying attention to the rest of the class (can be along with MG or AnQ)

Adou Administration (assign homework, return tests, passing out handouts, explaining/setting up activity, logistics, etc.)

RB Rapport building with students prior to class, or throughout class

W Waiting when there is an opportunity for an instructor to be interacting with or observing/listening to student or group activities and the instructor is not doing so - no doing something and could be

P Pausing to wait for students to think, understand the assignment, getting to work and on task, think/catch up, etc.

O Other - explain in comments

\section{Student Engagement (optionall)}

L Small fraction (10-20\%) obviously engaged.

M Substantial fractions both clearlyengaged and clearly not engaged.

H Large fraction of students $(80+\%)$ clearly

engaged in class activity or listening to instructor.

Suggestions regarding codes and comments:

- Clarify code choices with comments.

- Consider indicating your confidence regarding coding, especially when you aren't sure about choice of codes.

HOW TO USE OBSERVATION MATRIX: Put a check under all codes that happen anytime in each 2 minute time period (check multiple codes where appropriate). If no codes fit, choose "O" (other) and explain in comments. Put in comments when you feel something extra should be noted or explained.

1

${ }^{1}$ Adapted from the Classroom Observation Protocol for Undergraduate STEM - COPUS This protocol allows observers, after a short 1.5 hour training period, to reliably characterize how faculty and students are spending their time in the STEM classroom. ${ }^{\dagger}$ For further information, see: www.cwsei.ubc.ca/resources/COPUS.htm Smith MK, Jones FHM, Gilbert SL, and Wieman CE. 2013. The Classroom Observation Protocol for Undergraduate STEM (COPUS): a New Instrument to Characterize University STEM Classroom Practices. CBE-Life Sciences Education, Vol. 12(4), pp. 618-627 